\title{
Student's Skills of Innovative Thinking using Thermoelectric Devices for STEAM Education in ASEAN
}

\author{
Urai Seetawan ${ }^{1}$, Atiwat Seetawan ${ }^{2}$, Chatchavit Seetawan ${ }^{3}$, Kunchit Singsook ${ }^{4}$, Tosawat \\ Seetawan $^{5}$ \\ $\left\{\right.$ t_seetawan@snru.ac.th $\left.{ }^{1}\right\}$ \\ Thatnaraiwittaya School, 660 Nittayo Road, Mueang District, Saknon Nakhon, Thailand ${ }^{1,2,3}$, Program \\ of Physics, Saknon Nakhon Rajabhat University ${ }^{4}$, Thermoelectric Research Laboratory, Center of \\ Excellence on Alternative Energy, Research and Development Institute ${ }^{4,5}$
}

\begin{abstract}
The Science Technology Engineering the Arts and Mathematics (STEAM) education was trend to change from traditional education philosophy based on standardized test scores to a modern trade learning process. We proposed the innovative thinking skills for under graduate, graduate and high school students in ASEAN counties using new fabrication of thermoelectric device (TED) kit. The TED kit was developed to understand and create basic science and applied science knowledges such as energy, heat, heat converse to electricity, materials and micro generator and refrigerator applications. The 300 students from Indonesia, Myanmar, Vietnam, Loa, Cambodia and Thailand counties have ASEAN-TED Workshop 2018 in SakonNakonRajabhat University (SNRU), Thailand. They are most satisfaction with designing and fabricating thermoelectric cell and thermoelectric devices by them self to create a knowledge of technology and get new idea innovation. The workshop has impacted with students to fabricate new 18 thermoelectric prototypes developing to innovation show and competition in ASEAN-Thermoelectric device fabrication and invention fair 2018 on 1st August 2018 at SNRU every year.
\end{abstract}

Keywords: Innovative education; thermoelectric technology; STEM fields

\section{Introduction}

In the ASEAN counties; high school, colleges, and university have trained skills innovative thinking of young scientists similar to the World scientist education. The goal of this project is to develop a curriculum that integrates scientific training with creativity development to promote innovative cognitive skills in undergraduate science students. The Sakon Nakhon Rajabhat University (SNRU), Thailand is an ideal setting for the STEM and STEAM curriculum development (Madden 2013, Young Audiences Arts for Learning, 2018, Lonka, 2018). STEM education is integrated learning approach in which Science Technology Engineering and Mathematics in a discipline, separate, and discrete subjects into a cohesive learning paradigm based on real-world applications (Elaine, 2016, White, 2014).

STEAM education is integrated approach to learn uses Science, Technology, Engineering, Art and Mathematics as access points for guiding student inquiry, critical thinking and innovative thinking. The end results are students who take thoughtful risks, engage in 
experiential learning, persist in problem-solving, embrace collaboration, and work through the creative process. These are the innovators, educators, leaders, and learners of the $21^{\text {st }}$ century (Riley, 2018).

$21^{\text {st }}$ century skills are considered to be particularly important for success in academic contexts and on the job. These skills include primarily higher-order thinking skills and complex cognitive processes. They are considered very important by researchers and policy makers alike and include concepts such as creativity, problem solving, and information and communication technology (ICT) literacy (Greiff, 2015, Binkley, 2018, Piirto, 2018, Hakkaraine, 2000).

In this work, we proposed the ASEAN students' skills of innovative thinking using thermoelectric devices to learn uses science (Physics and Chemistry), Technology, Engineering, Art and Mathematics education in TED Fabrication Workshop 2018 and TE Invention Fair 2018 at SNRU, Thailand.

\section{Methodlogy}

\subsection{Thermoelectric Devices}

We created thinking about global warming, increasing pollution, increasing IC heat, the end of cheap oil problems and increasing energy demand in the world. Thermoelectric technology is conversed directly into different temperature to electricity and vice versa which opportunities for low grade heat harvesting and green energy production. For example, automobile waste heat thermoelectric power generation and on chip thermoelectric cooling. This technology is solid state construction (no moving parts), diffusion barriers, vibration free operation, no acoustical or electrical noise, size and performance output highly scalable of 2 $\mathrm{mm}$ to $60 \mathrm{~mm}$ and fully scalable $\mu \mathrm{W}$ to $\mathrm{kW}$ of heat pumping or power output depending on design. We need large electrical conductivity, high Seebeck coefficient and low thermal conductivity as following the dimensionless figure of merit;ZT $=\left(S^{2} T\right) / \rho \kappa$

where $\mathrm{S}$ is Seebeck coefficient, pelectrical resistivity, $\mathrm{T}$ is absolute temperature and $\kappa$ is thermal conductivity which all parameters different values in metals, insulators and semiconductors thermoelectric materials (Seetawan, 2015). Thermoelectric devices are used low, medium and high temperature depend on thermoelectric materials. Thermoelectric materials are synthesized by solid state reaction, hotpress, spark plasma and hydro thermal methods. Thermoelectric cell, module and devices are composed p-type and n-type thermoelectric materials connecting by copper or silver electrode to obtain the thermoelectric generator and thermoelectric refrigerator, as shown in Table 1. For example, thermoelectric application is micro generator, cooling computer, drink coolers, recharging devices, space probes, solar power, clothing. We developed thermoelectric device kit for the STEAM education using conference the ASEAN students' skills of innovative thinking to create new thermoelectric applications and invention. The thermoelectric device fabrication manual step by step is shown in Figure 1. After workshop, we managed the competition of the ASEAN TED fabrication and invention fair 2018 using the same students' groups are shown in Figure 2. 


\subsection{Participants}

We designed a self-reported questionnaire to measure students' skills of innovative thinking with thermoelectric devices using 315 students answered the questionnaire. The questionnaire was also measured before and after leaning keynote speaker talk and TED fabrication workshop.

\subsection{Assessments Instrument}

The self-report questionnaire composed of TE knowledge, time, keynote speaker, TED kit and staff of workshop, which called for rating on a five-point scale; $5:$ most, $4:$ much, 3 : medium, 2 : minor and 1 : least.

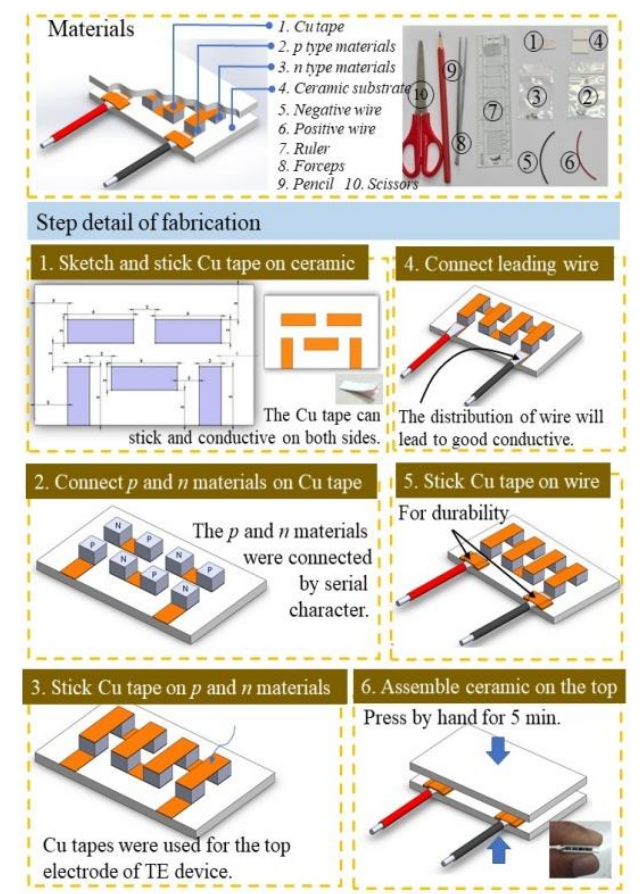

Fig. 1. Thermoelectric device fabrication manual and step detail of fabrication 


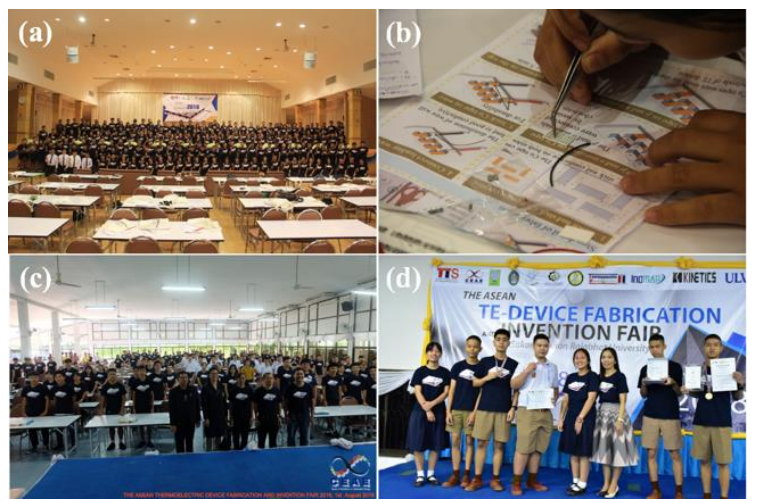

Fig.2. (a) the ASEAN TED Fabrication Workshop 2018, (b) Manual of TED Fabrication Workshop 2018 (c), the ASEAN TED Fabrication and Invention Fair 2018 and (d) Example of participant get awards

Table 1. Thermoelectric materials properties at room temperature

\begin{tabular}{cccccc}
\hline Type Name & $S\left(\mu \mathrm{V} \mathrm{K}^{-1}\right)$ & $\rho(\mu \Omega \mathrm{m})$ & $\kappa\left(\mathrm{W} \mathrm{m}^{-1} \mathrm{~K}^{-1}\right)$ & $Z T$ \\
\hline $\mathbf{p}$ & $\mathrm{Sb}_{2} \mathrm{Te}_{3}$ & 110 & 0.50 & 4.45 & 0.22 \\
$\mathbf{n}$ & $\mathrm{Bi}_{2} \mathrm{Te}_{3}$ & 40 & 10.16 & 1.17 & 0.06 \\
\hline
\end{tabular}

\section{Results And Discussion}

The ASEAN TED fabrication workshop 2018 has been increased interesting by participant form 2014-2018 which 315 persons assessed satisfaction for thermoelectric knowledge, appropriate time, keynote speaker, thermoelectric device kit and staff are shown in Figure 3. The ASEAN Invention Fair 2018 competition was organized by SNRU and Thai Thermoelectric Society (TTS), Thailand. In the competition, student participants consisting of various departments in ASEAN were contested to conduct thermoelectric fabrication so as to produce the greatest power possible. The workshop and competition were divided into two competition categories, namely 'Thermoelectric Device Fabrication Workshop' that is open to students in the ASEAN region and an exhibition of 'Thermoelectric Invention Fair' for all high school, undergraduate, and graduate students in the ASEAN. This workshop and competition were also attended by 112 teams (high school 73 teams and high education 39 teams) from several countries in the ASEAN. Among them are Indonesia, Myanmar, Laos, Vietnam and the host country's team, Thailand. A team was consisted three members such as a teacher and two students. In the race competition, student explained, each team is given a component to compile a thermoelectric fabrication kit. The TED kit was consisted alumina, cable, thermoelement, and copper. In the fabricating process, according to students' skills, each team is granted the freedom to develop their creativity in how the design, the p-n junctions (a type of thermoelectric materials), and the packaging from thermoelectric are to be made. After that, they are will test the power of each thermoelectric that has been made by each team to determine the winner of this competition. The team succeeded in winning the competition if successfully assembled and made the highest voltage thermoelectric module. 


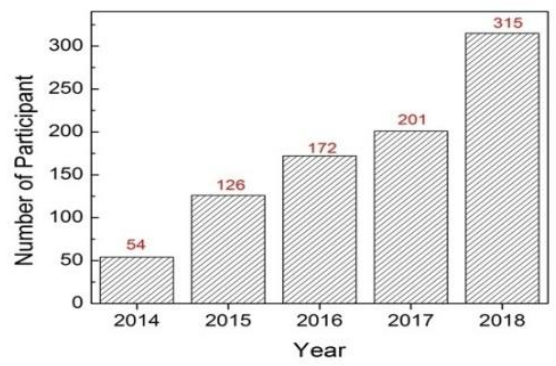

Fig.3. Year dependent number of participant ASEAN TED fabrication workshop and TE invention fair 2014-2018

All participants have been assessed satisfaction for thermoelectric knowledge, appropriate time, keynote speaker, thermoelectric device kit and coach or staff are shown in Fig. 4. It was found that high satisfaction level about 4, it means much satisfaction for thermoelectric knowledge, time, keynote speaker, TED kit and staffs.

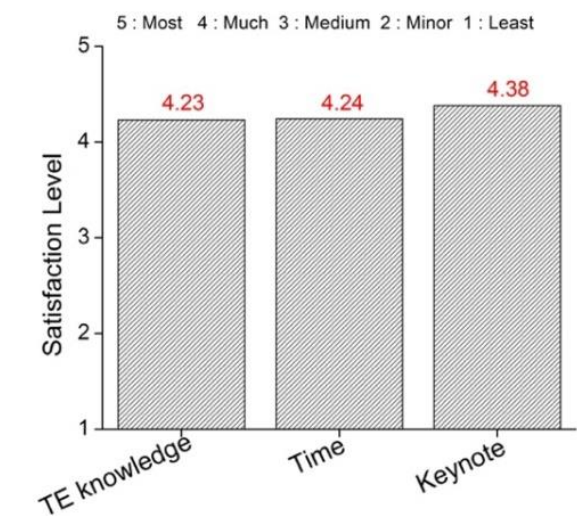

(a)

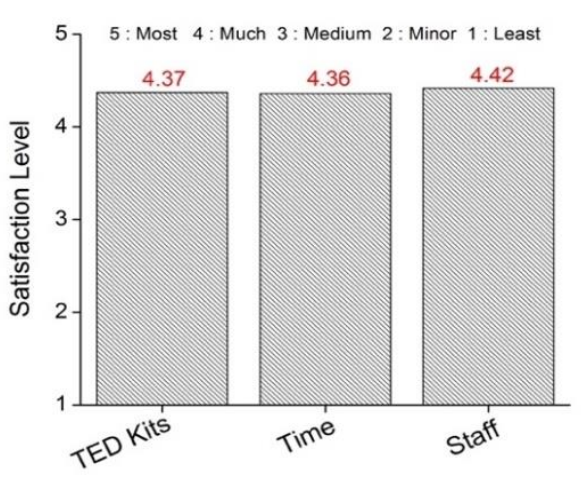

(b)

Fig. 4. The satisfaction (a) theoretical thermoelectric talk by keynote speaker (b) thermoelectric device kit for fabrication 
The awards gave the winner of high electrical power of TED and TE invention due to highly score assessed by international jury. In addition, we gave Gold, Silver and Bronze coins for TE invention depend on score level 80-100 (Gold), 70-80 (Silver) and 60-70 (Bronze), as shown in Figure 5.

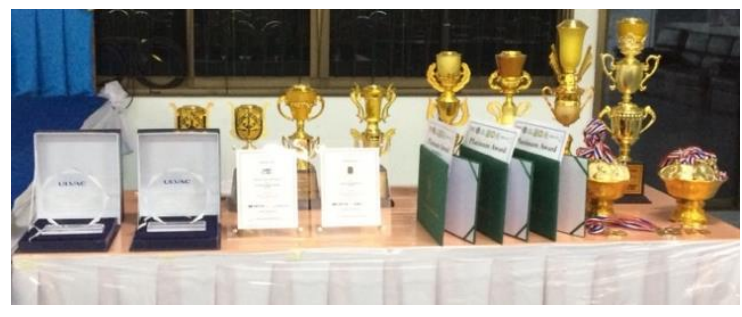

Fig.5. The awards ASEAN TED Fabrication Workshop 2018 and TE Innovation Fair 2018

\section{Conclusions}

The TED fabrication workshop and TE invention fair 2018 can increased skills innovative thinking and excellently tools supported the STEAM education for ASEAN students. The students can created idea and learned the science (Physics: energy, heat, heat transfer, electricity, semiconductor, solid state and particles, Chemistry: elements, chemical compositions, solutions, chemical reactions and solid state reactions), Technology (thermoelectric, alternative energy, renewable energy, small generator, small refrigerator and solid state air conditioner), Engineering: (design, maker and TE applications), Art: (drawing, conducting map and TE models), and Mathematics (number, area, volume, graphs and statistics). The study, give the limitation of self-report, indicates that a most satisfaction of the ASEAN students, TED very well and responsibility for STEAM education at school, college and university.

Acknowledgements. This work has financial supported Thai Thermoelectric Society (TTS), National Research Council of Thailand (NRCT), ULVAC (Thailand) Ltd. and Kinetics Corporation Ltd and Thailand Research Fund (TRF): TRF Research Career Development Grant, RSA (RSA6180070).

\section{References}

[1]Binkley M., Erstad O., Herman J., Raizen S., Martin R., Miller-Ricci M., Defining twenty-first century skills. in P. Griffin, B. McGaw, \& E. Care (Eds.), Assessment and teaching of 21st century skills (pp. 17-66). New York: Springer [Online], 2012.

Available: http://dx.doi.org/10.1007/978-94-007-2324-5.

[1]Elaine J. H.,2016. LiveScience Contributor, What is STEM Education?, February 11, 05:16pm ET, "STEMTEC". Fivecolleges.edu. Retrieved 2016-10-27, 2014.

[1]Greiff S., Niepel C., Wüstenberg S. August 12) "21st century skills: International advancements and recent developments," Thinking Skills and Creativity 18, 1-3, 2018. 
[1]Hakkarainen K., IlomaÈ ki L., Lipponen L., Muukkonen H., Rahikainen M., Tuominen T., Lakkala M., Lehtinen E., Students' skills and practices of using ICT: results of a national assessment in Finland," Computers \& Education 34, 103-117, 2000.

[1]Lonka K., Phenomenal Learning from Finland, Edita, Finland, 2018.

[1]MaddenM. E., BaxterM., BeauchampH., BouchardK., HabermasD., HuffM., LaddBr., PearonJ.,PlagueG., Rethinking STEM Education: An Interdisciplinary STEAM Curriculum, Procedia Computer Science 20, 541-546.

[1]Piirto J., Creativity for 21st century skills. Rotterdam: Sense Publishers [Online], 2018.

Available: http://dx.doi.org/10.1007/978-94-6091-463-8

[1]Riley S. M. (2018, August 12). STEAM Point: A Guide to Integrating Science, Technology, Engineering, the Arts, and Mathematics through the Common Core (2012), 2018.

[Online]. Available: https://educationcloset.com/steam/what-is-steam/.

[1]Seetawan T., Thermoelectric Technology, Chulalongkorn University Press, Bangkok, 1st edition, 2015.

[1]White D. W., What is STEM Education and Why is it Important?, Florida Association of Teacher Educators Journal 14, 1-9, 2014.

[1]Young Audiences Arts for Learning STEAM Caucus Briefing (2018, August 12). [Online]. Available: http://www.youngaudiences.org/why-arts/steam-congressional-briefing. 